\title{
Influence of Pressure on Near Nozzle Flow Field and Soot Formation in Laminar Co-Flow Diffusion Flames
}

\author{
A. Mansouri ${ }^{\mathrm{a}}$, N.A. Eaves ${ }^{\mathrm{b}}$, M.J. Thomson ${ }^{\mathrm{c}}$, and S.B. Dworkin ${ }^{\mathrm{a}}$ \\ ${ }^{a}$ Department of Mechanical \& Industrial Engineering, Ryerson University, Toronto, \\ Ontario, Canada, M5B 2K3; \\ ${ }^{b}$ Department of Mechanical, Automotive \& Materials Engineering, University of \\ Windsor, Windsor, Ontario, Canada, N9B 3P4; \\ ${ }^{c}$ Department of Mechanical \& Industrial Engineering, University of Toronto, Toronto, \\ Ontario, Canada M5S 3G8;
}

E-mail address: amin.mansouri@ryerson.ca (Amin Mansouri)

E-mail address: nickolas.eaves@uwindsor.ca (Nick A. Eaves)

E-mail address: murray.thomson@utoronto.ca (Murray J. Thomson)

*Corresponding author. E-mail address: seth.dworkin@ryerson.ca (Seth B. Dworkin). 


\section{Influence of Pressure on Near Nozzle Flow Field and Soot Formation in Laminar Co-Flow Diffusion Flames}

Soot formation from combustion devices, which tend to operate at high pressure, is a health and environmental concern, thus investigating the effect of pressure on soot formation is important. While most fundamental studies have utilized the coflow laminar diffusion flame configuration to study the effect of pressure on soot, there is a lack of investigations into the effect of pressure on the flow field of diffusion flames and the resultant influence on soot formation. A recent work has displayed that recirculation zones can form along the centreline of atmospheric pressure diffusion flames. This present work seeks to investigate whether these zones can form due to higher pressure as well, which has never been explored experimentally or numerically.

The CoFlame code, which models co-flow laminar, sooting, diffusion flames, is validated for the prediction of recirculation zones using experimental flow field data for a set of atmospheric pressure flames. The code is subsequently utilized to model ethane-air diffusion flames from 2 to $33 \mathrm{~atm}$. Above $10 \mathrm{~atm}$, recirculation zones are predicted to form. The reason for the formation of the zones is determined to be due to increasing shear between the air and fuel steams, with the air stream having higher velocities in the vicinity of the fuel tube tip than the fuel stream. This increase in shear is shown to be the cause of the recirculation zones formed in previously investigated atmospheric flames as well. Finally, the recirculation zone is determined as a probable cause of the experimentally observed formation of a large mass of soot covering the entire fuel tube exit for an ethane diffusion flame at $36.5 \mathrm{~atm}$. Previously, no adequate explanation for the formation of the large mass of soot existed.

Keywords: recirculation, laminar diffusion flame, soot model, ethane

\section{Introduction}

Soot formation during combustion processes is a concern due to several negative health and environmental effects of elevated atmospheric soot levels. Due to these adverse effects, there is a desire to reduce soot emissions from practical combustion devices, which tend to operate at elevated pressures. Thus, studying the effect of pressure on soot formation is important. 
There have been a number of recent experimental investigations on the effect of pressure on soot formation in a laminar co-flow flame configuration [1-17]. This configuration is utilized due to the simplified geometry, yet still allowing for investigation of the possible effects of diffusion and mixing. These studies concluded that maximum soot volume fraction increased with increasing pressure; however, the study by Joo and Gülder [6] had the interesting result of soot volume fraction reaching a peak at 55 atm, then monotonically declining as pressure was raised further. A brief communication by Mandatori and Gülder [18] demonstrated another unique phenomenon where at 36.5 atm the entire ethane fuel stream converted to soot.

To compliment these experimental investigations, multiple numerical studies have been performed to attempt and understand the reasons for the experimentally observed influence of pressure on soot formation. Most studies relied on simplified soot models that had limited ability to understand how the mechanisms of soot formation are influenced [16, 19-24]; however, others have used the more advanced method of moments [17] or sectional soot formation models $[15,25,26]$ that utilize Polycyclic Aromatic Hydrocarbon (PAH-based) soot nucleation and condensation models. One sectional soot formation code, CoFlame [27], has been validated and extensively used to investigate soot formation under a wide range of conditions, including high pressure. These advanced studies concluded that the experimentally observed increase in soot formation with increasing pressure was due to the positive feedback nature of soot formation, instigated by density increases. In addition, the study in [26] demonstrated the importance of extending the computational domain to model below the exit plane of the fuel tube and including a conjugate heat transfer (CHT) model within numerical simulations of high pressure sooting diffusion flames. However, there still has been no adequate explanation of the reason for the complete conversion of ethane at 36.5 atm observed in [18], even with the investigations of Eaves et al on these flames [25, 26]. 
To date, there are limited studies on the effect of pressure on the flow field of co-flow diffusion flames and the subsequent effect of the flow field on soot formation. In a very recent work, Xiong et al. [28] experimentally and numerically displayed that recirculation zones can form near the nozzle of atmospheric pressure co-flow laminar diffusion flames when the fuel density is greater than that of air. Additionally, they concluded that in order to numerically predict the recirculation zones, the computational domain should extend into the fuel tube, similar to the conclusions of [26]. Xiong et al. asserted that the cause of the recirculation zones was due to the negative buoyancy effects exerted on fuels with density greater than air. Since the density of methane is lower than that of air, due to a positive buoyancy effect, no recirculation zone has been formed. By contrast, propane is heavier than air and due to its higher relative density, a negative buoyancy effect causes recirculation zones along the centreline. The results from [28] raise the question if recirculation zones could be responsible for the complete conversion of ethane to soot observed in [18].

Since ethane is approximately the same density as air, there may be another mechanism that causes the observed recirculation zones in high pressure laminar diffusion flames. It should be noted that in the study by Xiong et al [28], constant mass flow rates for air and for fuel were used for all flames, thus fuels with higher densities would have lower flow velocities. Other researchers have noted the importance of selecting fuel and air mass flow rates such that the resultant flow velocities are matched to minimize shear effects $[29,30]$; however, it is not known if to what extent minimizing shear effects is necessary.

\subsection{Agenda}

In this present work, the CoFlame soot formation code [27], extensively validated at atmospheric pressure, and previously validated for soot volume fraction at elevated pressure against the data of Mandatori and Gülder [9], is utilized to investigate the 
potential of recirculation zones causing the observed complete conversion of ethane to soot. The influence of pressure on the size of any potential recirculation zones is explored, along with an explanation of the cause of the recirculation zone observed in this work and in [28].

\section{Flame and model description}

The flames chosen for this investigation are the steady, non-smoking, co-flow laminar ethane/air diffusion flames at pressures of 2 to 33 atm, studied experimentally by Mandatori and Gülder [9, 10]. Fuel and air mass flow rates are kept constant as pressure is varied, with values of $0.0052 \mathrm{~g} / \mathrm{s}$ for the fuel stream and $0.12 \mathrm{~g} / \mathrm{s}$ for $15 \mathrm{~atm}$ and below and $0.24 \mathrm{~g} / \mathrm{s}$ at higher pressures for the air stream. The increased air mass flow rate at higher pressures was required to achieve stable flames in the experiments. The computational domain used extends $3.45 \mathrm{~cm}$ in the axial direction and $1.18 \mathrm{~cm}$ in the radial direction, and is divided into 416 (z) x 172 (r) control volumes. A nonuniform mesh is used to save computational cost while still resolving large spatial gradients. The first $0.5 \mathrm{~cm}$ in the $\mathrm{z}$ direction is below the fuel tube exit plane. This distance is sufficient to ensure the temperature gradients at $\mathrm{z}=0.0$ (the bottom of the computational domain) are negligible.

In order to validate the model, the methane-air ethylene-air, and propane-air coflow laminar diffusion flames at atmospheric pressure studied by Xiong et al [28] are simulated. The air flow velocity is $6.2 \mathrm{~cm} / \mathrm{s}$, with methane, ethylene, and propane flow velocities of $4.45,2.21$, and $1.40 \mathrm{~cm} / \mathrm{s}$ respectively. Therefore, the velocity ratio, or shear between the fuel and air streams, is not constant between the different fuels, with the propane-air case having a higher air-fuel velocity ratio. The computational domain used extends $12.54 \mathrm{~cm}$ in the axial direction and $3.95 \mathrm{~cm}$ in the radial direction, and is divided into 320 (z) x 135 (r) control volumes. The first $1.0 \mathrm{~cm}, 1.0 \mathrm{~cm}$, and $2.0 \mathrm{~cm}$ in 
the $z$-direction is below the fuel tube exit plane for methane, ethylene, and propane, respectively. The distances are chosen to ensure the gradients at the inlet to the computational domain are near zero and any further increase in the distance does not affect computational results. For the propane flame, a longer distance was required to ensure insensitivity to the amount of fuel tube included in the computational domain. For all flames, top-hat velocity profiles are utilized for the air and fuel stream boundary conditions.

For the gaseous phase, the fully coupled elliptical conservation equations for mass, momentum, energy, and species mass fraction are solved. CoFlame [27] utilizes the axi-symmetrical nature of the flame, and equations are solved in the twodimensional ( $\mathrm{z}$ and $\mathrm{r}$ ) cylindrical co-ordinate system. Conjugate heat transfer between the solid fuel tube and the fuel and air streams is modelled using the harmonic mean method [26, 31]. The chemical kinetic mechanism that is used for this investigation is the one originally presented in [32], with modifications described in [33, 34].

Soot particle dynamics are described using a fixed sectional method, in which soot particle mass ranges are divided logarithmically into 35 discrete sections. The soot sectional model includes several processes, those being nucleation, PAH condensation and HACA surface growth, surface oxidation, coagulation, fragmentation, particle diffusion, and thermophoresis. In a recent work [35], soot nucleation and condensation were modified to result from 5-ring aromatic (A5) collisions, specifically benzo[a]pyrene (BAPYR), secondary benzo[a]pyrenyl (BAPYR*S), and benzo(ghi)fluoranthene (BGHIF), as opposed to from pyrene, with a non-unity nucleation efficiency, which resulted in better centreline soot predictions. All other soot phenomena, including nucleation, surface growth, PAH surface condensation, surface oxidation, coagulation, fragmentation, particle diffusion, thermophoresis, and particle radiation are modelled in the same fashion as in $[25,26,33,35-45]$. A detailed 
description of the governing equations, boundary conditions, solution methodology, and chemical mechanism can be found in previous works [27].

\section{Results and discussion}

\subsection{Flow field validation}

Validation computations are performed for the methane-air, ethylene-air, and propane- air diffusion flames. Figure 1 displays the flow streamlines near the fuel tube exit plane for the methane-air (lowest fuel-air velocity ratio) and the propane-air (highest fuel-air velocity ratio).

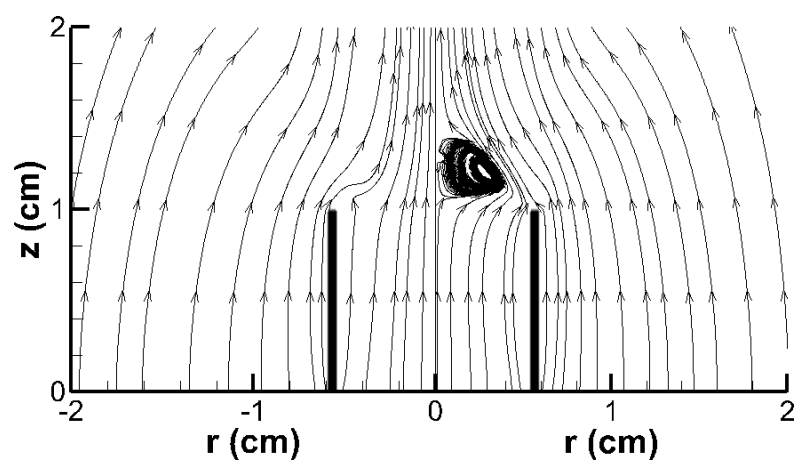

Figure 1: Computed flow streamlines for the CoFlame code near the fuel tube exit plane for an atmospheric methane-air diffusion flame on the left side, and an atmospheric propane-air flame on the right side.

The methane flame results display no recirculation zone, while the propane-air flame results display a recirculation zone along the center axis of the flame. Figure 1 demonstrates that the CoFlame model is able to capture the qualitative trend of the formation of a recirculation zone for propane, and non-formation for methane. Similar to the methane-air flame, no recirculation zone has been formed in the ethylene-air flame which can be explained due to a relatively close density of ethylene to that of air. Only for the propane-air flame has a recirculation zone been observed, which is due to the denser nature of propane compared to air. To validate the qualitative results shown in Fig. 1, a comparison between the fuel velocity with respect to radial position at a 
constant height above the burner $(\mathrm{z}=1 \mathrm{~mm})$ and axial position along the centreline has been provided in Fig. 2.
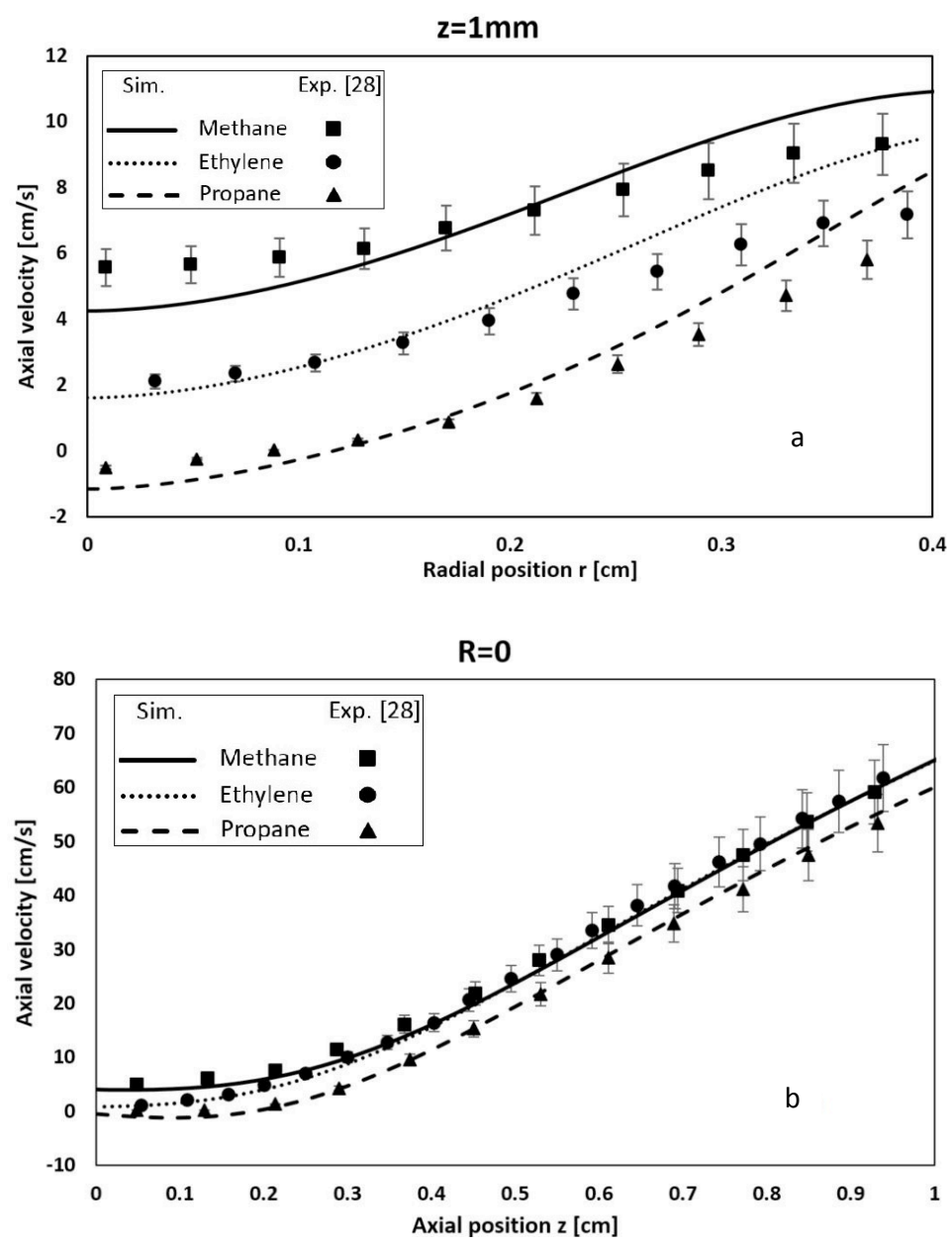

Figure 2: Comparison of the numerical and the experimental results of the radial ( $\mathrm{a}: \mathrm{at} \mathrm{z}$ $=1 \mathrm{~mm})$ and axial $(\mathrm{b}$ : at $\mathrm{R}=0)$ profiles of the axial velocity for methane, ethylene, and propane flames

The CoFlame code predicts the same results as in [28]. The chemical mechanism was chosen to ensure model consistency across all flames. The propane sub-mechanism used in the present work could capture bulk combustion properties of diffusion flames. This sub-mechanism has been validated in the literature [46]. Further agreement is seen between simulation and experiment in the present work. Figure 2 demonstrates the capability of the CoFlame model in capturing the correct quantitative trend of the experimental results for both methane and propane [28]. 


\subsection{Effect of pressure on flow field}

With the flow field predicted by the CoFlame code being validated, it is now applied to the ethane-air high pressure co-flow diffusion flames. For flames at 10 atm and above, a flow phenomenon is computationally observed at the exit plane of the fuel tube near the centreline region. Figure 3 displays streamlines for the 10, 15, 20, 25, 30, and $33 \mathrm{~atm}$ flames, zoomed in near the exit of the fuel tube (black region), which show the presence of a recirculation zone. This recirculation zone is not predicted at 2 atm or 5 atm flames; however, it is present for all other flames. It can be seen that the recirculation zone increases in size with increasing pressure. Additionally, as pressure increases, the streamlines near the fuel tube tip become increasingly more horizontal, directed towards the centreline. This is due to the thinning of the flame cross sectional area as pressure increases due to reductions in flame thickness with increasing pressure [25], thus the flow is accelerated inwards. In order to gain an understanding as to why these recirculation zones were predicted, two cold flow cases (where no flame is present and the entire domain is at 300 $\mathrm{K}$ ), utilizing the inlet flow conditions for the $10 \mathrm{~atm}$ and 33 atm flame respectively, are computed. For the two cold flow cases, in which no flame is present, the recirculation zones do not appear. These results indicate that the recirculation zone is being predicted due to the influence of the high temperature flame on the flow field, which is consistent with the results in [28]. Table 1 displays the ratio of the air flow velocity to the fuel flow velocity at the exit plane of the fuel tube near the tube tip in both hot and cold cases. The velocity for the fuel and air is taken at a location that is sufficiently far away from the fuel tube to no longer be in the boundary layer. In the hot cases, as pressure is increased, the ratio of air to fuel velocity increases. This result indicates that the shear between the air and fuel streams in the vicinity of the fuel tube increases with increasing pressure. The increase in the velocity ratio can be attributed to the high temperatures on the air side of the fuel tube (Ref [26] displayed temperatures of 
approximately $1700-1800 \mathrm{~K}$ ), causing the air velocity to increase. This effect is combined with the streamlines becoming more horizontal due to the change in flame cross sectional area, thus lowering the fuel velocity in the fuel tube tip region as well. The result is an increasing shear between the air and fuel streams as pressure increases. The increase in shear is accompanied by an increase in the size of the recirculation zone as well.
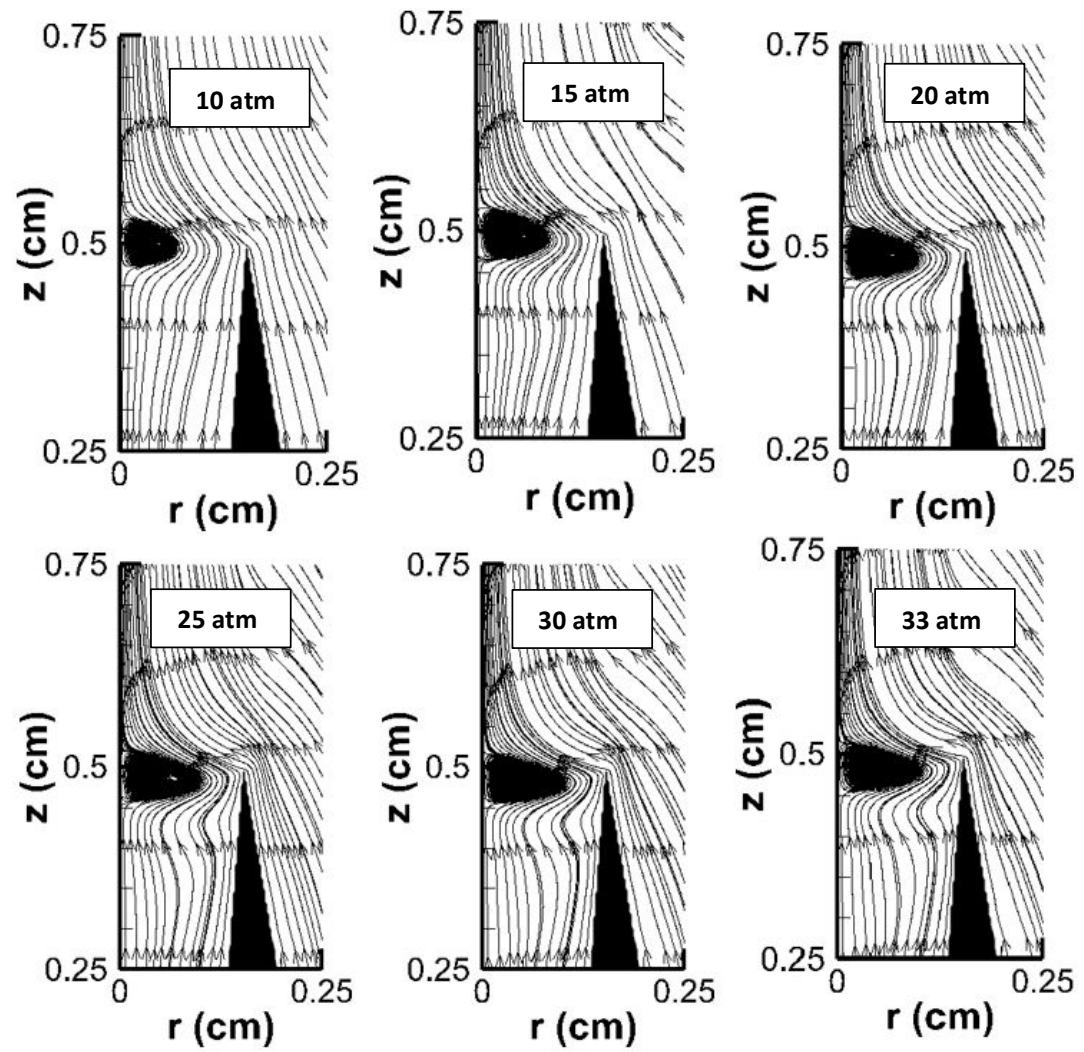

Figure 3: Computed flow streamlines with the CoFlame code near fuel tube tip for an ethane-air diffusion flame at 10 (top-left), 15 (top-middle), 20 (top-right), 25 (bottomleft), 30 (bottom-middle), and 33 (bottom-right) atm.

Given these two analyses, the following assertion with regards to the cause of the recirculation zones is made. The recirculation zones are caused by the increasing acceleration of the air near the fuel tube tip as pressure increases, due to high temperatures, combined with the thinning of the flame cross sectional area and subsequent flattening of the flow streamlines. These two effects cause significant shear between the air and fuel streams, causing the fuel stream to accelerate in the region near 
the fuel tube tip. In order for continuity to be upheld, there must be a corresponding deceleration of the fuel stream in the centreline region. Eventually, this required declaration is sufficiently large to cause the flow to reverse, and a recirculation zone forms.

Table 1: Ratio of Free-stream fluid velocity near fuel tube tip to average flow velocity in hot and cold cases

\begin{tabular}{ccc}
\hline $\begin{array}{c}\text { Pressure } \\
(\mathbf{a t m})\end{array}$ & $\begin{array}{c}\text { Velocity Ratio } \\
\text { Hot Cases }\end{array}$ & $\begin{array}{c}\text { Velocity Ratio } \\
\text { Cold Cases }\end{array}$ \\
\hline 2 & 2.12 & 1.83 \\
5 & 3.00 & 1.91 \\
10 & 3.42 & 2.05 \\
15 & 3.88 & 2.25 \\
20 & 7.92 & 4.06 \\
25 & 8.36 & 4.22 \\
30 & 8.88 & 4.30 \\
33 & 9.36 & 4.36 \\
\hline
\end{tabular}

Experimentally, it would be very difficult to detect the presence of these recirculation zones, as they are located in the centre of the flame, inside the fuel tube. This is contrary to the recirculation zones discovered in [28], as in that study the recirculation zones were fully above the exit plane of the fuel tube and detectable. It should be noted that while it would seem that simply reducing the air flow rate for experiments would reduce or eliminate the recirculation zones, there has to be consideration of flame stability as well. Most experiments at high pressure already utilized the minimum co-flow air required to obtain a stable flame [6-10], thus eliminating these recirculation zones may not be possible in some cases.

Based on the role of shear in the presence of the recirculation zones, it should be possible to induce a recirculation zone simply by increasing the air flow velocity, or reducing the fuel flow velocity. Since in the experiments in [28] a constant mass flow 
rate was used for all fuels, the fuel flow velocity was smaller for heavier fuels (propane) than lighter fuels (methane). This means that for the heavier fuels, the shear between the air and fluid streams was higher, and thus the recirculation zones for the heavy fuel flames were influenced by the increased shear rather than directly due to the increases in the fuel's density.

Another simulation is performed for the methane-air flame, except the air flow velocity is increased so that the ratio of the fuel to air velocities is the same as for the propane air case. For this simulation, a recirculation zone is not formed; however, upon increasing the air velocity by an additional factor of 2.25 , a recirculation zone forms. This result supports the theory that the recirculation zones are formed due to high local shear between the air and fuel fluid streams in the vicinity of the fuel tube.

\subsection{Relationship between recirculation zones and soot formation}

To determine the relationship between the recirculation zones and soot formation, the 5 atm flame is re-simulated with the co-flow air velocity increased by a factor of ten. This increase is sufficiently large to induce a recirculation zone, although not excessively large to induce turbulence (an increase by a factor of five did not induce a recirculation zone). Figure 4 displays the predicted soot volume fraction along the centreline of the flame with the experimental air flow rates and ten times the experimental rate and the experimental measurements [9]. There is a discrepancy between the experimental data and the computations at low axial heights; however, this can be attributed to the model not differentiating between nascent and mature soot. The experimental technique used to determine soot volume fraction is only sensitive to mature soot; however, the model lumps both nascent and mature soot into one entity [47]. Nascent soot tends to form in the lower temperature (less than 1300-1600 K) regions of flames, prior to formation of mature soot, thus the predicted large soot volume fraction at low axial heights is mostly 
nascent soot [48]. When the recirculation zone is present, there is an increase in soot volume fraction near the exit plane of the fuel tube (axial height $0.5 \mathrm{~cm}$ in the figure); however, at larger axial heights the difference between the peak soot volume fraction for the two cases is very minimal. In the experiment, the axial position of peak soot concentration is located at $0.65 \mathrm{~cm}$ above the burner. At this point, the experimental soot volume fraction is $81.6 \mathrm{ppm}$, while simulations with the regular and 10x air flow rate lead to the prediction of 75.1 and $77.1 \mathrm{ppm}$ respectively, thus demonstrating the effect of the recirculation zone in increasing peak soot volume fraction along the centreline.

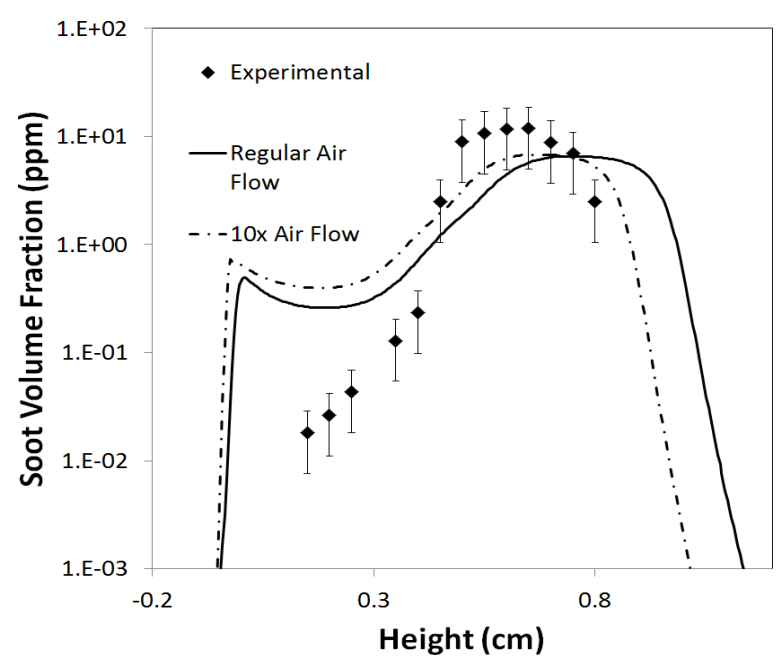

Figure 4: CoFlame computed centreline soot volume fraction profile compared with experimental data for ethane-air diffusion flames at 5 atm with experimental air flow rate and ten times the experimental flow rate. $[9,10]$

It should be noted that as pressure increases, peak soot volume fraction rises. This growth in the value of maximum soot concentration is due to formation of recirculation zones, as well as an increase in pressure. Differentiation between the effect of the recirculation zone and pressure is of interest. Thus, simulations have been conducted with the air flow rate reduced by a factor of 2 and 4 at 10,15, and 20 atm flames in an attempt to remove recirculation zones and study the effect of only pressure 
on soot concentration. Reducing the air flow rate at the mentioned simulations did not remove the recirculation zone. A limitation for reducing the air flow rate is the stability of the flame, which was jeopardized when applying a reduction factor more than 4 . Therefore, further differentiation between the effect of recirculation and pressure was not possible in the present study. Differentiation between the effect of the recirculation zone and pressure was restricted to manipulating the $5 \mathrm{~atm}$ flame, in an attempt to add the recirculation effect to it, as shown in Figure 4.

Figure 5 displays the predicted soot volume fraction along the centreline of the 10 and 33 atm ethane-air flames with the experimental air flow rates and the experimental measurements [9]. It can be seen that the calculations for the 33 atm flame predict a higher soot volume fraction in the recirculation zone than for the 10 atm flame. As pressure is increased, the recirculation zone increases, and a larger soot volume fraction is predicted in the zone. The results point to an explanation for the experimentally observed complete conversion of the flame to soot at $36.5 \mathrm{~atm}$ [18]. Calculations for the 36.5 atm flame were attempted; however, a converged solution could not be obtained. Prior to divergence, the predicted recirculation zone spanned the entirety of the fuel tube exit plane with a very large $\left(O\left(10^{3}\right) \mathrm{ppm}\right)$ soot volume fraction in the zone, which eventually lead to divergence. This leads to the assertion that the complete conversion to soot is caused by the recirculation zone. While the CoFlame code is not a transient solver, nor can it handle bulk solid phases, the trend of increasing soot in the recirculation zone as pressure increases and being unable to obtain a converged solution for the 36.5 atm flame support the stated assertion. To summarize, the effect of the recirculation zones on centreline soot formation is minimal up until the point the zone is sufficiently large to cause a complete conversion to soot. 


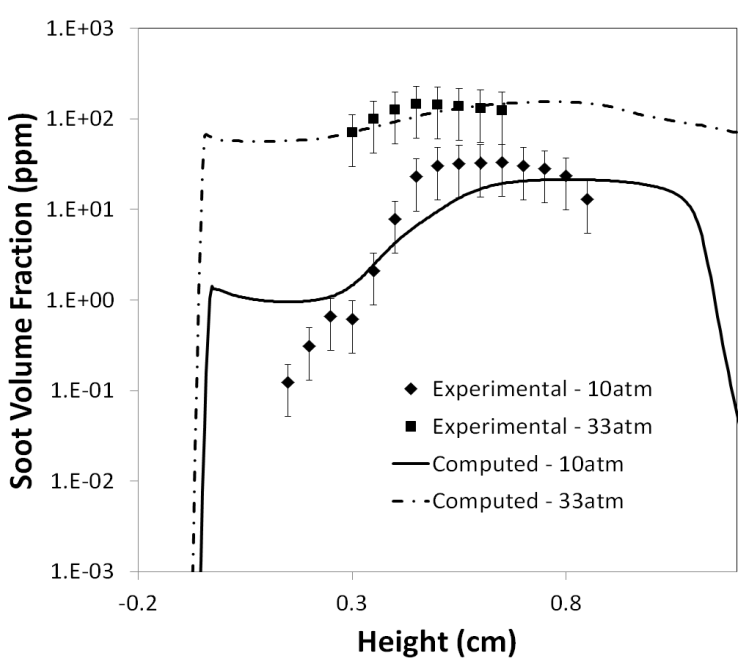

Figure 5: CoFlame computed centreline soot volume fraction profile compared with experimental data for ethane-air diffusion flames at 10 and 33 atm with experimental air flow rate. $[9,10]$

\section{Conclusions}

The effect of pressure on near nozzle flow field and soot formation in laminar diffusion flames is investigated numerically using the CoFlame code. The code is validated against previous experimental data for methane and propane diffusion flames in its ability to correctly predict the formation of recirculation zones. From 10 atm and greater, recirculation zones are predicted to form along the centreline of the flame near the exit plane of the fuel tube for ethane-air diffusion flames previously experimentally and numerically investigated. The recirculation zones are shown to be caused by the increased local shear between the fuel and air fluid streams, and not solely due to density differences between the fuel and air. The formed recirculation zones are therefore able to explain the experimentally observed complete conversion of ethane to soot at 36.5 atm, although the effect of the recirculation zones on soot formation is shown to be minimal otherwise. Future work should focus on verifying the effect of shear experimentally for atmospheric diffusion flames where the recirculation zone would be more easily detected. 


\section{Acknowledgments}

This research was undertaken, in part, thanks to funding from the Canada Research Chairs program. The authors acknowledge NSERC of Canada for additional financial support. Computations were performed on the Ryerson University Sandy Bridge computing cluster and the GPC supercomputer at the SciNet HPC Consortium. SciNet is funded by: The Canada Foundation for Innovation under the auspices of Compute Canada; the Government of Ontario; Ontario Research Fund - Research Excellence; and the University of Toronto.

\section{References}

[1] W.L. Flower, and C.T. Bowman, Soot production in axisymmetric laminar diffusion flames at pressures from one to ten atmospheres, Symposium (International) on Combustion 21 (1988), pp. 1115-1124.

[2] W. Lee, and Y.D. Na, Soot Study in Laminar Diffusion Flames at Elevated Pressure Using Two-Color Pyrometry and Abel Inversion, JSME International Journal Series B 43 (2000), pp. 550-555.

[3] L.L. McCrain, and W.L. Roberts, Measurements of the soot volume field in laminar diffusion flames at elevated pressures, Combustion and Flame 140 (2005), pp. 60-69.

[4] K.A. Thomson, Ö.L. Gülder, E.J. Weckman, R.A. Fraser, G.J. Smallwood, and D.R. Snelling, Soot concentration and temperature measurements in co-annular, nonpremixed CH4/air laminar flames at pressures up to $4 \mathrm{MPa}$, Combustion and Flame 140 (2005), pp. 222-232.

[5] H.I. Joo, and Ö.L. Gülder, Soot formation and temperature field structure in coflow laminar methane-air diffusion flames at pressures from 10 to 60atm, Proceedings of the Combustion Institute 32 (2009), pp. 769-775.

[6] ---, Soot formation and temperature structure in small methane-oxygen diffusion flames at subcritical and supercritical pressures, Combustion and Flame 157 (2010), pp. 1194-1201.

[7] H.I. Joo, and Ö.L. Gülder, Experimental study of soot and temperature field structure of laminar co-flow ethylene-air diffusion flames with nitrogen dilution at elevated pressures, Combustion and Flame 158 (2011), pp. 416-422.

[8] D.S. Bento, K.A. Thomson, and Ö.L. Gülder, Soot formation and temperature field structure in laminar propane-air diffusion flames at elevated pressures, Combustion and Flame 145 (2006), pp. 765-778.

[9] P.M. Mandatori, and Ö.L. Gülder, Soot formation in laminar ethane diffusion flames at pressures from 0.2 to $3.3 \mathrm{MPa}$, Proceedings of the Combustion Institute 33 (2011), pp. 577-584.

[10] P.M. Mandatori, Soot Formation in Ethane-air Coflow Laminar Diffusion Flames at Elevated Pressures, Library and Archives Canada = Bibliothèque et Archives Canada, 2006.

[11] Ö.L. Gülder, G. Intasopa, H.I. Joo, P.M. Mandatori, D.S. Bento, and M.E. Vaillancourt, Unified behaviour of maximum soot yields of methane, ethane and propane laminar diffusion flames at high pressures, Combustion and Flame 158 (2011), pp. 2037-2044. 
[12] A.E. Karataş, and Ö.L. Gülder, Soot formation in high pressure laminar diffusion flames, Progress in Energy and Combustion Science 38 (2012), pp. 818-845.

[13] A.E. Karataş, G. Intasopa, and Ö.L. Gülder, Sooting behaviour of n-heptane laminar diffusion flames at high pressures, Combustion and Flame 160 (2013), pp. 1650-1656.

[14] A.E. Karataş, and Ö.L. Gülder, Dependence of sooting characteristics and temperature field of co-flow laminar pure and nitrogen-diluted ethylene-air diffusion flames on pressure, Combustion and Flame 162 (2015), pp. 1566-1574.

[15] F. Liu, A.E. Karataş, Ö.L. Gülder, and M. Gu, Numerical and experimental study of the influence of $\mathrm{CO} 2$ and $\mathrm{N} 2$ dilution on soot formation in laminar coflow C2H4/air diffusion flames at pressures between 5 and 20atm, Combustion and Flame 162 (2015), pp. 2231-2247.

[16] M.R.J. Charest, Ö.L. Gülder, and C.P.T. Groth, Numerical and experimental study of soot formation in laminar diffusion flames burning simulated biogas fuels at elevated pressures, Combustion and Flame 161 (2014), pp. 2678-2691.

[17] H. Guo, Z. Gu, K.A. Thomson, G.J. Smallwood, and F.F. Baksh, Soot formation in a laminar ethylene/air diffusion flame at pressures from 1 to 8 atm, Proceedings of the Combustion Institute 34 (2013), pp. 1795-1802.

[18] P.M. Mandatori, and Ö.L. Gülder, Complete conversion of ethane to soot in a coflow laminar diffusion flame at 3.65 MPa, Combustion and Flame 150 (2007), pp. 400-403.

[19] F. Liu, K.A. Thomson, H. Guo, and G.J. Smallwood, Numerical and experimental study of an axisymmetric coflow laminar methane-air diffusion flame at pressures between 5 and 40 atmospheres, Combustion and Flame 146 (2006), pp. 456-471.

[20] M.R.J. Charest, H.I. Joo, Ö.L. Gülder, and C.P.T. Groth, Experimental and numerical study of soot formation in laminar ethylene diffusion flames at elevated pressures from 10 to 35atm, Proceedings of the Combustion Institute 33 (2011), pp. 549-557.

[21] M.R.J. Charest, C.P.T. Groth, and Ö.L. Gülder, A computational framework for predicting laminar reactive flows with soot formation, Combustion Theory and Modelling 14 (2010), pp. 793-825.

[22] M.R.J. Charest, Numerical Modelling of Sooting Laminar Diffusion Flames at Elevated Pressures and Microgravity. Doctor of Philosophy, University of Toronto, 2010.

[23] M.R.J. Charest, C.P.T. Groth, and Ö.L. Gülder, Effects of gravity and pressure on laminar coflow methane-air diffusion flames at pressures from 1 to 60 atmospheres, Combustion and Flame 158 (2011), pp. 860-875.

[24] ---, A numerical study on the effects of pressure and gravity in laminar ethylene diffusion flames, Combustion and Flame 158 (2011), pp. 1933-1945.

[25] N.A. Eaves, A. Veshkini, C. Riese, Q. Zhang, S.B. Dworkin, and M.J. Thomson, A numerical study of high pressure, laminar, sooting, ethane-air coflow diffusion flames, Combustion and Flame 159 (2012), pp. 3179-3190.

[26] N.A. Eaves, M.J. Thomson, and S.B. Dworkin, The Effect of Conjugate Heat Transfer on Soot Formation Modeling at Elevated Pressures, Combustion Science and Technology 185 (2013), pp. 1799-1819.

[27] N.A. Eaves, Q. Zhang, F. Liu, H. Guo, S.B. Dworkin, and M.J. Thomson, CoFlame: A refined and validated numerical algorithm for modeling sooting laminar coflow diffusion flames, Computer Physics Communications 207 (2016), pp. 464-477. 
[28] Y. Xiong, M.S. Cha, and S.H. Chung, Fuel density effect on near nozzle flow field in small laminar coflow diffusion flames, Proceedings of the Combustion Institute 35 (2015), pp. 873-880.

[29] M.D. Smooke, M.B. Long, B.C. Connelly, M.B. Colket, and R.J. Hall, Soot formation in laminar diffusion flames, Combustion and Flame 143 (2005), pp. 613-628.

[30] R.K. Abhinavam Kailasanathan, J. Zhang, T. Fang, and W.L. Roberts, Effects of Diluents on Soot Surface Temperature and Volume Fraction in Diluted Ethylene Diffusion Flames at Pressure, Combustion Science and Technology 186 (2014), pp. 815-828.

[31] S.V. Patankar, Numerical Heat Transfer and Fluid Flow, Hemisphere, New York (1980).

[32] N.A. Slavinskaya, and P. Frank, A modelling study of aromatic soot precursors formation in laminar methane and ethene flames, Combustion and Flame 156 (2009), pp. 1705-1722.

[33] S.B. Dworkin, Q. Zhang, M.J. Thomson, N.A. Slavinskaya, and U. Riedel, Application of an enhanced PAH growth model to soot formation in a laminar coflow ethylene/air diffusion flame, Combustion and Flame 158 (2011), pp. 1682-1695.

[34] N.A. Slavinskaya, U. Riedel, S.B. Dworkin, and M.J. Thomson, Detailed numerical modeling of PAH formation and growth in non-premixed ethylene and ethane flames, Combustion and Flame 159 (2012), pp. 979-995.

[35] M. Saffaripour, A. Veshkini, M. Kholghy, and M.J. Thomson, Experimental investigation and detailed modeling of soot aggregate formation and size distribution in laminar coflow diffusion flames of Jet A-1, a synthetic kerosene, and n-decane, Combustion and Flame 161 (2014), pp. 848-863.

[36] Q. Zhang, H. Guo, F. Liu, G.J. Smallwood, and M.J. Thomson, Modeling of soot aggregate formation and size distribution in a laminar ethylene/air coflow diffusion flame with detailed PAH chemistry and an advanced sectional aerosol dynamics model, Proceedings of the Combustion Institute 32 (2009), pp. 761768.

[37] M. Saffaripour, M. Kholghy, S.B. Dworkin, and M.J. Thomson, A numerical and experimental study of soot formation in a laminar coflow diffusion flame of a Jet A-1 surrogate, Proceedings of the Combustion Institute 34 (2013), pp. 1057-1065.

[38] V. Chernov, Q. Zhang, M.J. Thomson, and S.B. Dworkin, Numerical investigation of soot formation mechanisms in partially-premixed ethylene-air co-flow flames, Combustion and Flame 159 (2012), pp. 2789-2798.

[39] V. Chernov, M.J. Thomson, S.B. Dworkin, N.A. Slavinskaya, and U. Riedel, Soot formation with $C 1$ and $C 2$ fuels using an improved chemical mechanism for PAH growth, Combustion and Flame 161 (2014), pp. 592-601.

[40] N.A. Eaves, S.B. Dworkin, and M.J. Thomson, The importance of reversibility in modeling soot nucleation and condensation processes, Proceedings of the Combustion Institute 35 (2015), pp. 1787-1794.

[41] A. Veshkini, S.B. Dworkin, and M.J. Thomson, A soot particle surface reactivity model applied to a wide range of laminar ethylene/air flames, Combustion and Flame 161 (2014), pp. 3191-3200.

[42] A. Khosousi, and S.B. Dworkin, Detailed modelling of soot oxidation by $\mathrm{O} 2$ and $\mathrm{OH}$ in laminar diffusion flames, Proceedings of the Combustion Institute 35 (2015), pp. 1903-1910. 
[43] Q. Zhang, M.J. Thomson, H. Guo, F. Liu, and G.J. Smallwood, Modeling of Oxidation-Driven Soot Aggregate Fragmentation in a Laminar Coflow Diffusion Flame, Combustion Science and Technology 182 (2010), pp. 491-504.

[44] Q. Zhang, H. Guo, F. Liu, G.J. Smallwood, and M.J. Thomson, Implementation of an advanced fixed sectional aerosol dynamics model with soot aggregate formation in a laminar methane/air coflow diffusion flame, Combustion Theory and Modelling 12 (2008), pp. 621-641.

[45] F. Liu, S.B. Dworkin, M.J. Thomson, and G.J. Smallwood, Modeling DME Addition Effects to Fuel on PAH and Soot in Laminar Coflow Ethylene/Air Diffusion Flames Using Two PAH Mechanisms, Combustion Science and Technology 184 (2012), pp. 966-979.

[46] K.M. Leung, and R.P. Lindstedt, Detailed kinetic modeling of C1 - C3 alkane diffusion flames, Combustion and Flame 102 (1995), pp. 129-160.

[47] M.R. Kholghy, J. Weingarten, and M.J. Thomson, A study of the effects of the ester moiety on soot formation and species concentrations in a laminar coflow diffusion flame of a surrogate for B100 biodiesel, Proceedings of the Combustion Institute 35 (2015), pp. 905-912.

[48] M. Kholghy, M. Saffaripour, C. Yip, and M.J. Thomson, The evolution of soot morphology in a laminar coflow diffusion flame of a surrogate for Jet A-1, Combustion and Flame 160 (2013), pp. 2119-2130. 